\title{
Pattern metrics for a transdisciplinary landscape ecology
}

\author{
Kurt Riitters
}

Received: 6 November 2018/Accepted: 17 November 2018/Published online: 28 November 2018

(C) This is a U.S. government work and its text is not subject to copyright protection in the United States; however, its text may be subject to foreign copyright protection 2018

Three decades ago I became interested in measuring the spatial patterns of sun-flecks to estimate canopy light transmission. While many measurement approaches and pattern metrics had been described (e.g., Peitgen and Saupe 1988; Glassner 1990; Pickover 1990; Turner and Gardner 1991; Gonzalez and Woods 1992), there was no comprehensive software implementation of them. I wrote a computer program to calculate many of those metrics (and added a few of my own) using undercanopy photographs, but an opportune discussion with Bob O'Neill resulted in my never applying the program for that purpose. Bob's explanation of landscape ecology was encouraging, and his advice was characteristically sage and succinct: "The pattern stuff is good, but you're working at the wrong scale."

I tell that story for two reasons. First, it was how I discovered landscape ecology, and second, writing the program taught me some things about the pattern metrics that were being used in landscape ecology. To put it bluntly, the program had to measure only four things-map composition, attribute adjacency, patch area, and patch perimeter-in order to calculate all of the landscape ecology metrics. As a result, the metrics had to be correlated, especially since many of their

\section{K. Riitters $(\square)$}

USDA Forest Service, Southern Research Station,

Research Triangle Park, NC 27709, USA

e-mail: kriitters@fs.fed.us computing formulas were only minor algebraic variations of another metric's formula. Furthermore, it was clear from geometric packing constraints that map composition was a critical aspect of pattern. These intuitive notions were confirmed by empirical comparisons of pattern metrics over the next decade (e.g., Gustafson and Parker 1992; Riitters et al. 1995; Cain et al. 1997; Hargis et al. 1998).

Eric Gustafson's review (Gustafson 1998) brought some order to the then-chaotic evolution of landscape pattern metrics. He noted that no matter how they are measured, the fundamental elements of landscape pattern are map composition and spatial configuration. While Eric was referring to raster and point maps, his point applies equally well to other data models. For example, in graph theory (e.g., Keitt et al. 1997; Urban and Keitt 2001), composition is represented by the graph vertices and configuration by the graph edges. For 3-dimensional raster data (e.g., Myers et al. 1997; McGarigal et al. 2009), composition is analogous to the surface mean and configuration is analogous to the surface texture. ${ }^{1}$ Even the ecological and statistical

\footnotetext{
${ }^{1}$ There are deeper connections between these data models because raster maps are spatially-explicit graphs. On a 2-dimensional raster map, a focal class cell is a graph vertex and a patch of focal cells is a connected graph component; a 3-dimensional raster map is a hierarchical graph in which sets of connected components form an (inverted) dendrogram in the third dimension.
} 
discussions of habitat loss versus fragmentation per se (e.g., Fahrig 2003; Koper et al. 2007) are essentially concerned with composition (habitat area) and configuration (habitat fragmentation).

By now, it is well established that amount (composition) and adjacency (configuration) are fundamental, yet investigators often overlook them on the way to using other metrics that are deemed "appropriate" to elucidate the causes or effects of pattern in a given study. Similarly, it is well established that pattern is scale-dependent, but that is usually taken as a reason to choose one particular scale that is deemed "appropriate." As a result, we know a lot about pattern analysis and the causes or effects of pattern in particular circumstances. But I doubt that we will achieve transdisciplinary integration (sensu Wu 2013) of that knowledge if our common language (sensu Ostrom 2009) of pattern is based on potentially ambiguous metrics (sensu Bogaert 2003) and inconsistent implementations of them (sensu Riitters et al. 2000b). In the same way that mutual understanding requires a common language, transdisciplinary integration requires consistent methodology, and achieving that consistency should be a high priority in landscape ecology. It is appropriate to consider the characteristics and implementations of landscape pattern metrics that would help us to achieve Wu's (2013) vision of landscape ecology as transdisciplinary science.

Wu (2006) recognized that solid disciplinary foundations are essential to the success of transdisciplinary research. That means we must know how to measure and interpret pattern per se. But success also means we must conduct a pattern analysis in a way that facilitates, or at least does not hinder, integration between interdisciplinary research (e.g., between natural and social sciences) and participation from stakeholders. The larger problem is complicated because not all the questions about patterns can be known in advance, there is neither a preferred scale for measuring the patterns nor a preferred perspective for interpreting them, and the values placed upon patterns will vary from place to place. Based on my experiences participating in interdisciplinary ecological assessments, I suggest the primary objective of a pattern analysis is to quantify and map fundamental metrics of pattern in order to answer three questionsWhich patterns occur where? Over what spatial scales do the patterns exist? How are the patterns changing over time? The pattern analysis has to be agnostic and flexible with respect to worldviews, and capable of being reified and adapted for applications in a variety of disciplines. Thus, a good metric is robust to pattern, is transparent and thereby easy to interpret with respect to pattern, is not redundant of other metrics, and is interpretable with respect to many disciplinespecific questions as well as questions posed at higher levels. A good implementation reveals pattern as landscape context, preserves the spatial resolution of the input data, is applied at multiple spatial scales, maintains compatibility between metrics at the "focal class" and "landscape" levels, and produces maps of the results.

Given that composition and configuration are the fundamental elements of pattern, what are the fundamental metrics of composition and configuration, and how should they be measured? I will attempt to answer those questions by heuristic reinterpretation of concepts that are well established in the literature. For example, Neel et al. (2004) explored the behavior of a variety of focal class metrics on simulated binary maps with different combinations of focal class amount and adjacency. They showed that the values of many metrics depend strongly on amount and adjacency, and used the information to group the metrics according to behavioral similarity across gradients of amount and adjacency. Their interpretations were robust and informative, and they emphasized that amount and adjacency had to be important because of the way their simulations were constructed. But a re-interpretation of their results is that, at least for the scope of patterns measured by all the metrics they considered, amount and adjacency are the fundamental metrics of pattern. After all, if amount and adjacency are a good basis for simulating patterns, then they must also be a good basis for measuring patterns. Furthermore, they showed that one has to measure amount and adjacency anyway, in order to interpret differences in other metrics. Finally, since they showed that other metrics can usually be estimated from amount and adjacency, why measure the redundant metrics?

What can be inferred about landscape patterns from measurements of amount and adjacency? Looking at some example maps may help to answer that question. Using procedures similar to Neel et al. (2004), I used the multifractal option in the RULE model (Gardner 




(b)

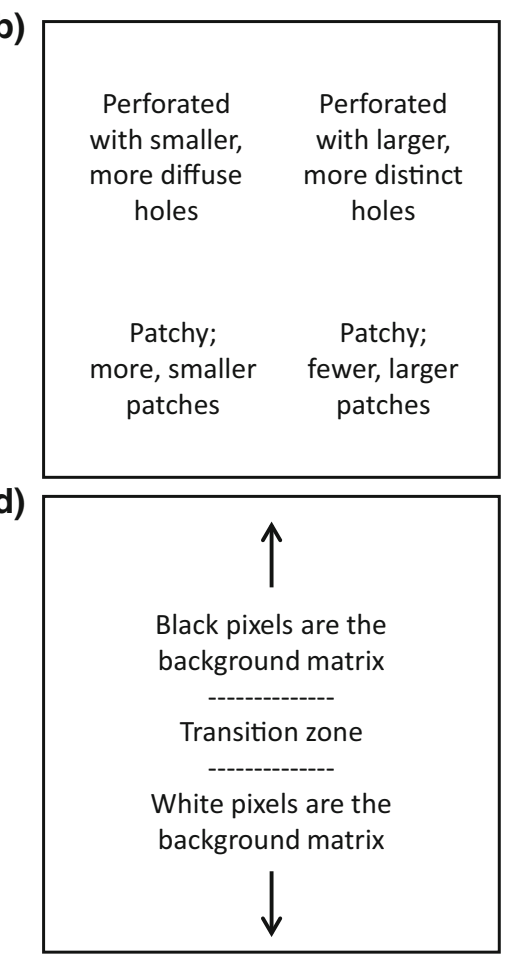

(c)

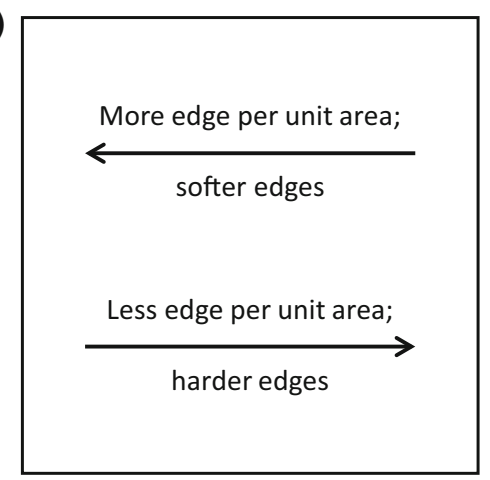

(e)

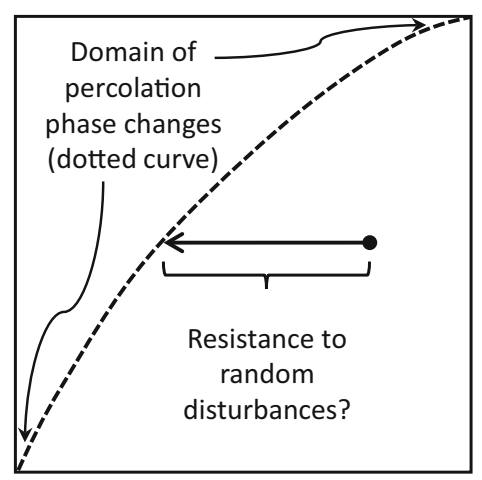

Fig. 1 a Twenty-five simulated maps are arranged in a twodimensional metric space defined by the amount and the adjacency of the black pixels within each map. Sub-regions of

1999) to produce 25 example maps for a factorial combination of five levels of amount $(P x=\{0.05$, $0.25,0.50,0.75,0.95\})$ and five levels of adjacency $(H x=\{0.00,0.25,0.50,0.75,1.00\})$. In Fig. 1a, the 25 maps are arranged in the metric space defined by the amount and adjacency of the focal class. Along the vertical axis, $P x$ (the proportion of the map occupied by the focal class $x$ ) is the measure of amount. Along that same metric space can be labeled according to patch characteristics (b), edge characteristics (c), dominance (d), and percolation phase changes (e)

the horizontal axis, adjacency is represented by Pxx, the conditional probability that a focal class pixel is adjacent to another focal class pixel. ${ }^{2}$ By just looking

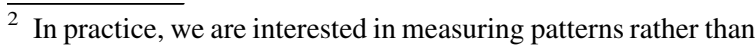
simulating them. In the RULE model, $H x$ is the Hurst exponent used to generate a 3-dimensional fractional Brownian surface, which is then segmented (sliced horizontally) to form a
} 
at the examples in Fig. 1a, it appears that measurements of amount and adjacency should support inferences about patches and perforations (Fig. 1b), edge density and hardness (Fig. 1c), and dominance (Fig. 1d). None of that is surprising, and there are other examples of what might be inferred about other aspects of pattern (e.g., Neel et al. 2004). While fully accounting for patch-level patterns (e.g., patch arrangement and perimeter complexity) naturally requires additional measurements of the patches (e.g., Hargis et al. 1998), these aspects of landscape pattern are clearly less fundamental since the mere existence of patches depends upon both amount and adjacency.

Percolation theory is another well-known topic in landscape ecology (Gardner et al. 1987) that invites reinterpretation. In Fig. 1e, the dotted curve ${ }^{3}$ is the domain of percolation phase changes, because a completely random arrangement of focal class pixels on a binary raster map guarantees the focal class is at a tipping point (phase change) of percolation. ${ }^{4}$ Since many aspects of pattern are certain to be significantly affected in predictable ways by phase changes everywhere in this domain (Gardner et al. 1987; Turner et al. 2001; Neel et al. 2004; Riitters et al. 2007), the interesting question for a landscape near that domain is not about the existence of a percolating cluster but rather about which ecological processes are likely to be affected by a phase change of percolation. For the ecological processes that are known to depend on percolation, or on aspects of pattern that are related to percolation, some answers to that question could be deduced from the observed $P x$. For that $P x$, the phase change occurs only for specific lattice geometries and neighbor rules (Plotnick and Gardner 1993). A unidirectional process (e.g., water flow) is impacted at a

Footnote 2 continued

2-dimensional binary "multifractal" map containing the target $P x$. Unfortunately, it is difficult to reverse the process; a 3-dimensional property like $H x$ is difficult to measure on a 2-dimensional map. $P x x$ is an analogous metric of adjacency which is referred to in popular software as "percentage of like adjacencies" (McGarigal et al. 2012) and "P22" (Vogt and Riitters 2017).

3 Danny C. Lee (personal communication) derived the equation for the curve in Fig. 1e. For a completely random arrangement of focal class pixels, and for any neighbor rule or map extent, $P x x=\frac{1}{\left(\frac{2}{2}\right)-1}$ for Px in $(0,1]$.

${ }^{4}$ On almost all finite subsets of an infinite map. larger $P x$ value than an omnidirectional process (e.g., pollen dispersal) (Plotnick and Gardner 1993). The connectivity of the "core" component of a given focal class is impacted at a larger $P x$ value than the "edge" component (Riitters et al. 2007). The species at risk of sudden loss of habitat (focal class) connectivity could be the ones with a corresponding movement rule (neighbor rule) and home range size (map extent). Irrespective of the initial landscape pattern, completely random disturbance (and recovery) will always drive a landscape towards the domain of phase changes. It is therefore plausible to measure landscape pattern resistance to random disturbances (and recovery) by the distance from that landscape to the domain where phase changes are guaranteed to occur (i.e., by the length of the arrow in Fig. 1e) (Zurlini et al. 2006). It is intriguing to contemplate whether that distance is related to the degree of apparent "dampening" of percolation-mediated phase changes on maps with different degrees of adjacency (Neel et al. 2004; Riitters et al. 2009a).

Turning now to the implementation of pattern analysis, it is well known that geographic tiling (including the definition of a specific study area) invites the modifiable areal unit problem (MAUP) (Jelinski and Wu 1996), but it is not often acknowledged that the implicit assumption of pattern stationarity within a tile ignores potential boundary effects. With a moving window measurement device (Baker and Cai 1992; Riitters et al. 1997), metrics are measured within a fixed-area surrounding window surrounding each focal class pixel, and the results are mapped at the subject pixel's location. As a result, the MAUP is largely postponed until after the patterns are measured, and landscape patterns are perceived and measured as contextual attributes which vary continuously over geographic space. When such measurements of Px and Pxx are mapped in the pattern metric space (Fig. 1), the local pattern context of each pixel is indicated by its location in the metric space, and the variance of local patterns is indicated by the dispersion of pixels across the metric space (Riitters et al. 2000a).

Every landscape ecologist also knows that patterns change with measurement scale, but if the perception of landscape pattern by an organism or ecological process involves "looking" at multiple scales simultaneously (Montello 1993), then any single-scale measurement is at best only a partial description of pattern. Therefore, it is worth considering which 
additional aspects of pattern could be measured by implementing a moving window with several window sizes. ${ }^{5}$ Such measurements of $P x$ alone constitute the probability-density function, the basis for an entire class of fractal pattern metrics (Milne 1992). By adding window size as a third dimension to the metric space in Fig. 1, focal class pixels can be grouped according to the similarity of their trajectories through that space to identify and geographically map the scale domains of focal class patterns (sensu Wu 2004) and the locations of scale-dependent transitions from global to local patterns (Zurlini et al. 2007). Such groupings can also identify patterns that describe the perimeters and juxtaposition of patches in a landscape (Riitters 2005; Riitters et al. 2017). Measurement scale can also be varied in terms of lag distance instead of window size (Dungan et al. 2002), such that a multiscale analysis of $P x x$ describes the sizes and spatial distribution of focal class patches (Zhang and Guindon 2017).

The above discussion was developed at the binary focal class level but it is easily extended to the landscape level. Briefly, pattern is a landscape property, focal class pattern is a subset of landscape pattern, and binary maps are a special case of categorical maps. Thus, on categorical maps the fundamental landscape level metrics are the vector of proportions $\boldsymbol{P} x(x=1 \ldots N$ classes $)$ and the attribute adjacency matrix $\boldsymbol{P} x y(x, y=1 \ldots N$ classes $) . \boldsymbol{P} x y$ is constructed by tabulating pairs of adjacent pixels according to their $\{x, y\}$ identities for some adjacency rule (e.g., 8-neighbor) (Musick and Grover 1991). At the landscape level, moving window measurements are taken in the vicinity of all pixels instead of only focal class pixels, thus enabling consistency between landscape-level and class-level analyses. Examples of applying $\boldsymbol{P} x$ include quantifying and mapping fragmentation (Riitters et al. 2002, 2015; Riitters and Wickham 2012), landscape mosaics (Riitters et al. 2000b, 2009b; Vogt and Riitters 2017), and anthropogenic interface zones (Yemshanov et al. 2015; Riitters and Costanza 2018). Analysis of Pxy yields landscape-level and class-level measures of entropy, texture, and contagion (Riitters et al. 1996; McGarigal et al. 2012). Because the individual elements of $\boldsymbol{P} x y$ provide information about "unlike adjacencies" as

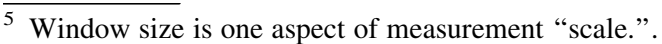

well as "like adjacencies," information from $\boldsymbol{P} x y$ can supports thematic analysis such as riparian forest (forest-water edges) (Riitters et al. 2011) and the proximate causes of forest fragmentation (naturalanthropogenic edges) (Wade et al. 2003).

In conclusion, landscape pattern is fundamentally information about landscape composition and landscape configuration which vary continuously over geographic space and observation scale. My experiences lead me to use amount and adjacency as the fundamental metrics of landscape pattern, and a multiscale moving window measurement device. Amount is a more fundamental metric than adjacency because a change in any other pattern metric cannot be interpreted reliably without accounting for changes of amount. These metrics and this implementation may constitute a minimum pattern analysis in the sense of adequately representing many of the known dimensions of pattern, but their sufficiency for representing all possible dimensions of pattern is necessarily an open question. Of course, my experiences could all be misleading because they are based primarily on raster land-cover maps, macro-scale analysis, and interdisciplinary assessments, but it remains that finding whatever may be the true simplicity at the core of the "pattern onion" is prerequisite to achieving an unambiguous transdisciplinary dialogue.

Acknowledgements I am indebted to Jim Wickham, Peter Vogt, Bob O'Neill, John Coulston, Jennifer Costanza, Tim Wade, and Bruce Jones.

\section{References}

Baker WL, Cai Y (1992) The r.le programs for multiscale analysis of landscape structure using the GRASS geographical information system. Landscape Ecol 7:291-302

Bogaert J (2003) Lack of agreement on fragmentation metrics blurs correspondence between fragmentation experiments and predicted effects. Ecol Soc 7(1):r6

Cain DH, Riitters KH, Orvis K (1997) A multi-scale analysis of landscape metrics. Landscape Ecol 12:199-212

Dungan JL, Perry JN, Dale MRT, Legendre P, Citron-Pousty S, Fortin M-J, Jakomulska A, Miriti M, Rosenberg MS (2002) A balanced view of scale in spatial statistical analysis. Ecography 25:626-640

Fahrig L (2003) Effects of habitat fragmentation on biodiversity. Annu Rev Ecol Evol Syst 34:487-515

Gardner RH (1999) RULE: a program for the generation of random maps and the analysis of spatial patterns. In: Klopatek JM, Gardner RH (eds) Landscape ecological 
analysis: issues and applications. Springer, New York, pp 280-303

Gardner RH, Milne BT, Turner MG, O’Neill RV (1987) Neutral models for the analysis of broad-scale landscape pattern. Landscape Ecol 1:19-28

Glassner AS (1990) Graphics gems. Academic Press, Boston

Gonzalez RC, Woods RE (1992) Digital image processing. Addison-Wesley, Reading

Gustafson EJ (1998) Quantifying landscape spatial pattern: what is the state of the art? Ecosystems 1:143-156

Gustafson EJ, Parker GR (1992) Relationships between landcover proportion and indices of landscape spatial pattern. Landscape Ecol 7:101-110

Hargis CD, Bissonette JA, David JL (1998) The behavior of landscape metrics commonly used in the study of habitat fragmentation. Landscape Ecol 13:167-186

Jelinski DE, Wu J (1996) The modifiable areal unit problem and implications for landscape ecology. Landscape Ecol 11:129-140

Keitt TH, Urban DL, Milne BT (1997) Detecting critical scales in fragmented landscapes. Ecol Soc 1(1):4

Koper N, Schmiegelow FKA, Merrill EH (2007) Residuals cannot distinguish between ecological effects of habitat amount and fragmentation: implications for the debate. Landscape Ecol 22:811-820

McGarigal K, Cushman SA, Ene E (2012) FRAGSTATS v4: spatial pattern analysis program for categorical and continuous maps. Computer software program produced by the authors at the University of Massachusetts, Amherst. http:// www.umass.edu/landeco/research/fragstats/fragstats.html

McGarigal K, Tagil S, Cushman SA (2009) Surface metrics: an alternative to patch metrics for the quantification of landscape structure. Landscape Ecol 24:433-450

Milne BT (1992) Spatial aggregation and neutral models in fractal landscapes. Am Nat 139:32-57

Montello DR (1993) Scale and multiple psychologies of space. In: Frank AU, Campari I (eds) Spatial information theory a theoretical basis for GIS. COSIT 1993, vol 716. Lecture notes in computer science. Springer, Berlin

Musick HB, Grover HD (1991) Image textural measures as indices of landscape pattern. In: Turner MG, Gardner RH (eds) Quantitative methods in landscape ecology. Springer, New York

Myers W, Patil GP, Joly K (1997) Echelon approach to areas of concern in synoptic regional monitoring. Environ Ecol Stat 4:131-152

Neel MC, McGarigal K, Cushman SA (2004) Behavior of classlevel landscape metrics across gradients of class aggregation and area. Landscape Ecol 19:435-455

Ostrom E (2009) A general framework for analyzing sustainability of social-ecological systems. Science 325:419-422

Peitgen H-O, Saupe D (1988) The science of fractal images. Springer, New York

Pickover CA (1990) Computers, pattern, chaos and beauty. St. Martin's Press, New York

Plotnick RE, Gardner RH (1993) Lattices and landscapes. In: Gardner RH (ed) Lectures on mathematics in the life sciences, volume 23: predicting spatial effects in ecological systems, vol 23. American Mathematical Society, Providence, RI, pp 129-157
Riitters K, Costanza J (2018) The landscape context of family forests in the United States: anthropogenic interfaces and forest fragmentation from 2001 to 2011. Landsc Urban Plan. https://doi.org/10.1016/j.landurbplan.2018.04.001

Riitters K, Coulston J, Wickham J (2011) Fragmentation of forest communities in the eastern United States. For Ecol Manage 263:85-93

Riitters K, Vogt P, Soille P, Estreguil C (2009a) Landscape patterns from mathematical morphology on maps with contagion. Landscape Ecol 24:699-709

Riitters K, Vogt P, Soille P, Kozak J, Estreguil C (2007) Neutral model analysis of landscape patterns from mathematical morphology. Landscape Ecol 22:1033-1043

Riitters K, Wickham J, Costanza JK, Vogt P (2015) A global evaluation of forest interior area dynamics using tree cover data from 2000 to 2012. Landscape Ecol 31:137-148

Riitters K, Wickham J, Wade T (2009b) An indicator of forest dynamics using a shifting landscape mosaic. Ecol Ind 9:107-117

Riitters KH (2005) Downscaling indicators of forest habitat structure from national assessments. Ecol Ind 5:273-279

Riitters KH, Costanza JK, Buma B (2017) Interpreting multiscale domains of tree cover disturbance patterns in North America. Ecol Ind 80:147-152

Riitters KH, O’Neill RV, Hunsaker CT, Wickham JD, Yankee DH, Timmins SP, Jones KB, Jackson B (1995) A factor analysis of landscape pattern and structure metrics. Landscape Ecol 10:23-39

Riitters KH, O’Neill RV, Jones KB (1997) Assessing habitat suitability at multiple scales: a landscape-level approach. Biol Cons 81:191-202

Riitters KH, O’Neill RV, Jones KB, Wickham JD (1996) A note on contagion metrics for landscape analysis. Landscape Ecol 11:197-202

Riitters KH, Wickham JD (2012) Decline of forest interior conditions in the conterminous United States. Sci Rep 2:653

Riitters KH, Wickham JD, O'Neill RV, Jones KB, Smith ER (2000a) Global-scale patterns of forest fragmentation. Ecol Soc 4(2):3

Riitters KH, Wickham JD, O'Neill RV, Jones KB, Smith ER, Coulston JW, Wade TG, Smith JH (2002) Fragmentation of continental United States forests. Ecosystems 5:815-822

Riitters KH, Wickham JD, Vogelmann JE, Jones KB (2000b) National land-cover pattern data. Ecology 81:604

Turner MG, Gardner RH (1991) Quantitative methods in landscape ecology. Springer, New York

Turner MG, Gardner RH, O'Neill RV (2001) Landscape ecology in theory and practice: pattern and process. Springer, New York

Urban D, Keitt T (2001) Landscape connectivity: a graph-theoretic perspective. Ecology 82:1205-1218

Vogt P, Riitters K (2017) GuidosToolbox: universal digital image object analysis. Eur J Remote Sens 50:352-361

Wade TG, Riitters KH, Wickham JD, Jones KB (2003) Distribution and causes of global forest fragmentation. Ecol Soc $7(2): 7$

Wu J (2004) Effects of changing scale on landscape pattern analysis: scaling relations. Landscape Ecol 19:125-138

Wu J (2006) Landscape ecology, cross-disciplinarity, and sustainability science. Landscape Ecol 21:1-4 
Wu J (2013) Key concepts and research topics in landscape ecology revisited: 30 years after the Allerton Park workshop. Landscape Ecol 28:1-11

Yemshanov D, Koch FH, Riitters KH, McConkey B, Huffman T, Smith S (2015) Assessing land clearing potential in the Canadian agriculture-forestry interface with a multi-attribute frontier approach. Ecol Ind 54:71-81

Zhang Y, Guindon B (2017) Detecting and quantifying extended landscape structure with spatial co-occurrence surfaces. Pattern Anal Appl 20:519-529
Zurlini G, Riitters K, Zaccaralli N, Petrosillo I, Jones K, Rossi L (2006) Disturbance patterns in a socio-ecological system at multiple scales. Ecol Complex 3:119-128

Zurlini G, Riitters K, Zaccarelli N, Petrosillo I (2007) Patterns of disturbance at multiple scales in real and simulated landscapes. Landscape Ecol 22:705-721 